\title{
Biogeochemical Proxies of Anthropic Impact in Mediterranean Forest Soils
}

\author{
P. Tinoco ${ }^{1}$, A. Piedra Buena ${ }^{1}$, M. C. Zancada ${ }^{1}$, J. Sanz ${ }^{2}$ \& G. Almendros \\ ${ }^{1}$ Centro de Ciencias Medioambientales (CSIC), Serrano 115B, 28006 Madrid, Spain, and ${ }^{2}$ Instituto de Química Orgánica General \\ (CSIC), Juan de la Cierva 3, 28006 Madrid, Spain
}

\begin{abstract}
Quantitative changes in soil organic matter (SOM) from undisturbed Mediterranean forests and neighbouring deforested sites were assessed by analysing soil lipids and humic acids (HAs), in total studying 80 variables. Changes in the composition of free lipids reflected vegetation types, whereas HAs analysed by visible and ${ }^{13} \mathrm{C}$ NMR spectroscopy, sodium perborate degradation and Curie-point pyrolysis indicated the extent of structural alteration of lignin in soil. The molecular fractions released by degradation techniques applied to HAs showed that demethoxylation and oxidation were associated with the removal of forest vegetation, and the aromatic compounds consisted mainly of methoxyphenols and benzenecarboxylic acids. Decreased concentration of alkanes and increased amounts of alcohols were observed after removal of forests. The chain lengths of alkyl compounds also tended to decrease. In forest soil, there was a series of diterpene resin acids, whereas in pasture soil steroids from animal origin and a root-derived triterpenoids with friedelan structure were found. In relation to the total quantity and quality of soil $\mathrm{C}$, the overall chemical descriptors indicated that clearing and cultivation (semiarid cereal fields) lead to intense mineralization of SOM (mainly particulate, free organic matter) but the residual humic substances have enhanced maturity in terms of structural condensation and potential resilience. Conversely, the cleared forest soil under pasture had a comparatively higher potential for $\mathrm{C}$ sequestration, but the HA characteristics suggested selective preservation of plant biomacromolecules directly incorporated as underground biomass.
\end{abstract}

Keywords: Decomposition, cultivation, deforestation, humic acids, grassland, monitoring

\section{Introduction}

Identification of descriptors sensitive to the effect of soil use and management (such as removal of forest vegetation and cultivation) is not a trivial matter in the case of soils subjected to recent anthropogenic perturbations. In biogeochemical terms, the quantitative assessment of soil resilience requires the determination of the extent to which soil characteristics reflect a series of features related to the changing structure of the trophic system. In the case of cultivated soils, these changes are expected to be connected to the removal of the original vegetation, the new soil physical conditions after the continuous mechanical disruption of soil epipedon and the periodic inputs of chemical fertilizers, crop wastes or other organic amendments (Cerri et al., 1991; Desjardins et al., 1994; Veldkamp, 1994; Zukowska \& Flis-

Correspondence: G. Almendros. E-mail: humus@ccma.csic.es Received May 2010; accepted after revision May 2010
Bujak, 2002; Bertoncini et al., 2008; Figueiredo et al., 2008; Kawasaki et al., 2008; Pardo et al., 2008; Valtinat et al., 2008; Apezteguía et al., 2009; D’Angelo et al., 2009; Hamer et al., 2009; Pajares et al., 2009). The present article represents an exploratory experimental appraisal of the impact of deforestation (i.e. removal of the original vegetation) of Mediterranean forests in Central Spain through chemical descriptors. The aim was to assess the extent to which these alternative soil uses produced changes in the quantity and quality of different soil organic matter (SOM) fractions, which could be discussed in terms of resilience, sustainability or soil carbon sequestration under different management practices. Molecular assemblages corresponding to these descriptors were obtained from three progressively more complex organizational levels of the SOM: (i) direct extraction with organic solvents (total free lipid), which is expected to reflect the most recent changes in the structure of the trophic system; (ii) oxidative degradation of humic acids (HAs) with sodium perborate, which 
releases volatile compounds amenable to study by gas chromatography combined with mass spectrometry (GC/MS); and (iii) analytical pyrolysis combined with GC/MS (Py-GC/MS), which is assumed to provide information on recalcitrant, $\mathrm{C}-\mathrm{C}$ linked structures.

\section{Materials and methods}

\section{Experimental design, sample collection and soil general analysis}

A series of soil samples from four ecosystems representative of the original and current status of Mediterranean forest soils after transformation into cereal crops or pastures ( > 30 yr) were selected: soil 1-OF (seminatural evergreen oak forest) was Calcaric Cambisol, soil 1-CC was the deforested evergreen oak forest used for cereal cultivation, soil 2-AF (ash forest) was Epigleyc Cambisol and deforested soil 2-PS was a neighbouring pasture (Table 1). In both cases, the distance between seminatural and cultivated sampling sites was less than $50 \mathrm{~m}$; when present, soil litter was removed, and two composite samples per site were prepared by mixing up to four individual subsamples taken about $10 \mathrm{~m}$. Soil samples were dried at room temperature and homogenized to $2 \mathrm{~mm}$ before standard physico-chemical analyses (INEA, 1973).

The mechanical analysis was carried out following Kilmer \& Alexander (1949), after removal of SOM by treatments with dilute $\mathrm{H}_{2} \mathrm{O}_{2}$. The water retention of soil was calculated as water holding capacity, that is the difference in the water retained by the soil at 1.0 and at 0.1 bar. Water drop penetration time was determined by adding a water drop on the surface of the soil sample and measuring the time elapsed for the drop to be completely absorbed by soil (Savage et al., 1972). When the drop penetration time was more than $300 \mathrm{~s}$, the soil was considered to have water repellency (Wallis \& Horne, 1992).

Soil $\mathrm{pH}$ was measured in a 1:2.5 (w:v) soil:water ratio (INEA, 1973). The total content of carbonates was determined with a Bernard calcimeter (Guitián \& Carballas, 1976). Total $\mathrm{N}$ was determined by micro-Kjeldahl digestion and the soil $\mathrm{C}$ by wet oxidation using $1 \mathrm{~mol} / \mathrm{L} \mathrm{K}_{2} \mathrm{Cr}_{2} \mathrm{O}_{7}$ in acid medium and further redox titration (Nelson \& Sommers, 1982). The available $\mathrm{K}^{+}, \mathrm{Na}^{+}, \mathrm{Ca}^{2+}$ and $\mathrm{Mg}^{2+}$ were

Table 1 Differences between general characteristics of the sampling sites in seminatural Mediterranean forests and derived neighbouring agroecosystems

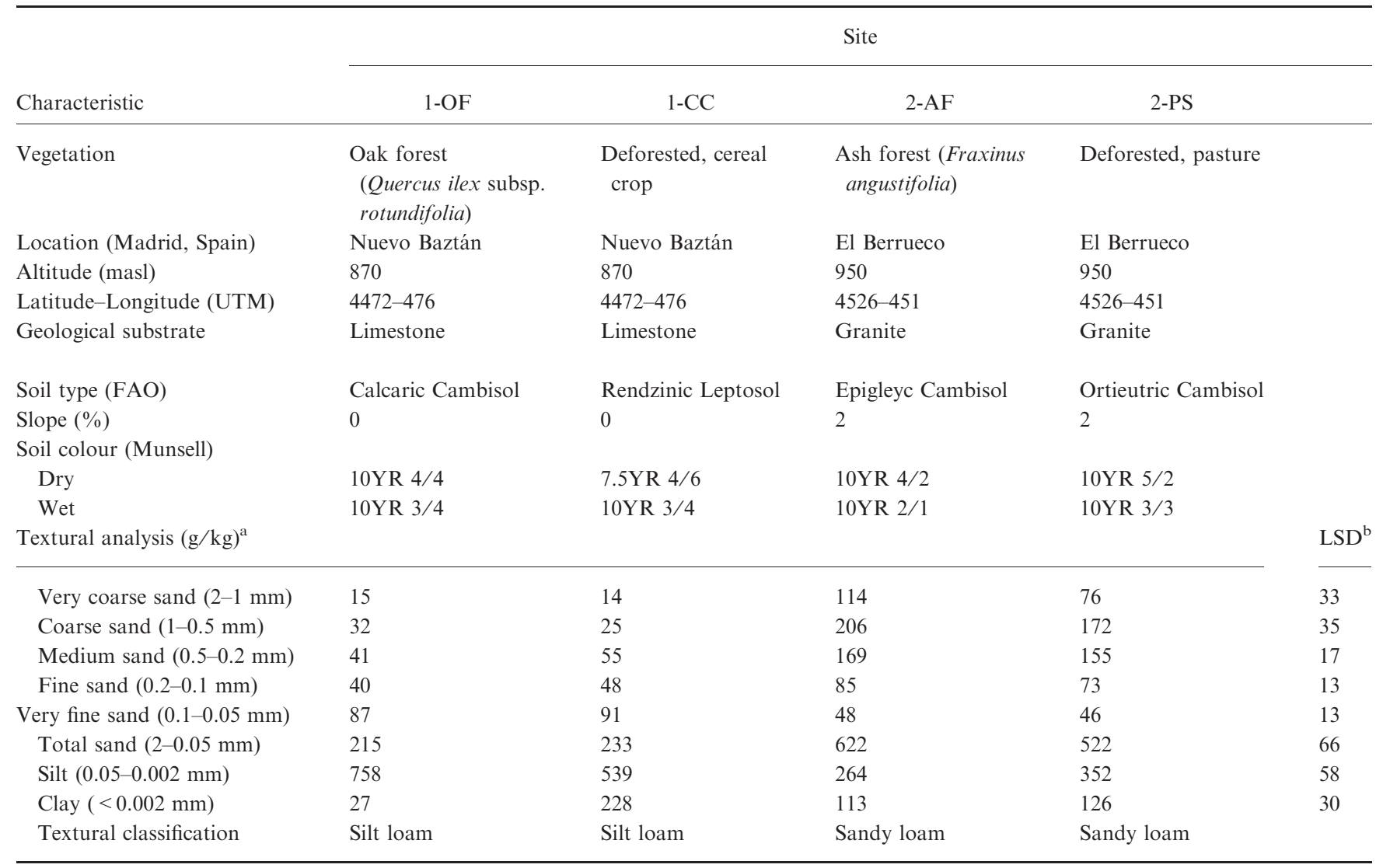

UTM, Universal Transverse Mercator; ${ }^{\text {a } U n i t e d ~ S t a t e s ~ D e p a r t m e n t ~ o f ~ A g r i c u l t u r e ; ~}{ }^{\mathrm{b}}$ Least significant difference $(P<0.05)$ calculated from soil composite samples and corresponding to two spatial replications. 
extracted with $1 \mathrm{~mol} / \mathrm{L} \mathrm{NH}_{4} \mathrm{OAc}$ at $\mathrm{pH}=7$ and cation exchange capacity (CEC) was determined (Juo et al., 1976; Page et al., 1982). Sodium and $\mathrm{K}^{+}$were determined by flame ionization spectroscopy, and $\mathrm{Ca}^{2+}$ and $\mathrm{Mg}^{2+}$ by atomic absorption spectroscopy. Sum of bases $(S)$ was calculated as $S=\mathrm{K}^{+}+\mathrm{Na}^{+}+\mathrm{Ca}^{2+}+\mathrm{Mg}^{2+}$, and the base saturation was determined as $(S / C E C) \times 100$. The $\mathrm{H}^{+}$content (exchange acidity) was determined by difference $\left(\mathrm{H}^{+}=\mathrm{CEC}-\mathrm{S}\right)$.

\section{Isolation and analysis of the lipid compounds}

Soil lipids were isolated and analysed in order to characterize their distribution patterns and to check for diagnostic biomarker compounds suitable to reflect differences between the formation processes of the SOM in the different ecosystems studied. The soil lipids were extracted from samples of $c a .50 \mathrm{~g}$ of soil using petroleum ether $\left(40-60{ }^{\circ} \mathrm{C}\right)$ for $24 \mathrm{~h}$, in $250-\mathrm{cm}^{3}$ Soxhlet. This solvent was used in order to prevent the co-extraction of brown-coloured macromolecular material that is removed with more polar solvents, which makes it necessary to purify the lipid (leading to selective sample losses) prior to GC. The extraction liquid was changed every $12 \mathrm{~h}$. The total extract obtained was subjected to dehydration with anhydrous $\mathrm{Na}_{2} \mathrm{SO}_{4}$ and evaporation under reduced pressure to approximately $50 \mathrm{~cm}^{3}$ before drying under $\mathrm{N}_{2}$ stream at room temperature (20$25^{\circ} \mathrm{C}$ ) and weighed.

For gas chromatographic analyses, the lipid samples were suspended in the minimal volume of methanol and methylated (three-fold) with ethereal diazomethane generated from Diazald (Schnitzer, 1974). The lipid compounds were separated and identified by GC/MS using an HP 5890 chromatograph connected to an HP 5971 mass detector (EI, $70 \mathrm{eV}$ ) and equipped with an $25 \mathrm{~m} \times 0.22 \mathrm{~mm}$ internal diameter, cross-linked OV-1 column. Helium flow was adjusted to $1 \mathrm{~cm}^{3} / \mathrm{min}$; the oven temperature was programmed from 70 to $220{ }^{\circ} \mathrm{C}$ at $4{ }^{\circ} \mathrm{C} / \mathrm{min}$ during the chromatographic run. For quantitative measurements, additional injections of replicated samples were made in a GC with a flame ionization detector. The identity of the compounds was assessed by their EI mass spectra at $70 \mathrm{eV}$, using the Wiley (2005) spectral database for comparison.

\section{Macromolecular soil organic matter fractions}

The quantitative determination of the particulate and alkaliextractable SOM fractions was based on classical procedures (Dabin, 1971; Duchaufour \& Jacquin, 1975), and is outlined in Figure 1. The separation of the low density, particulate, non-humic fraction, consisting of particles of plant residues at their early stages of transformation, that is free organic

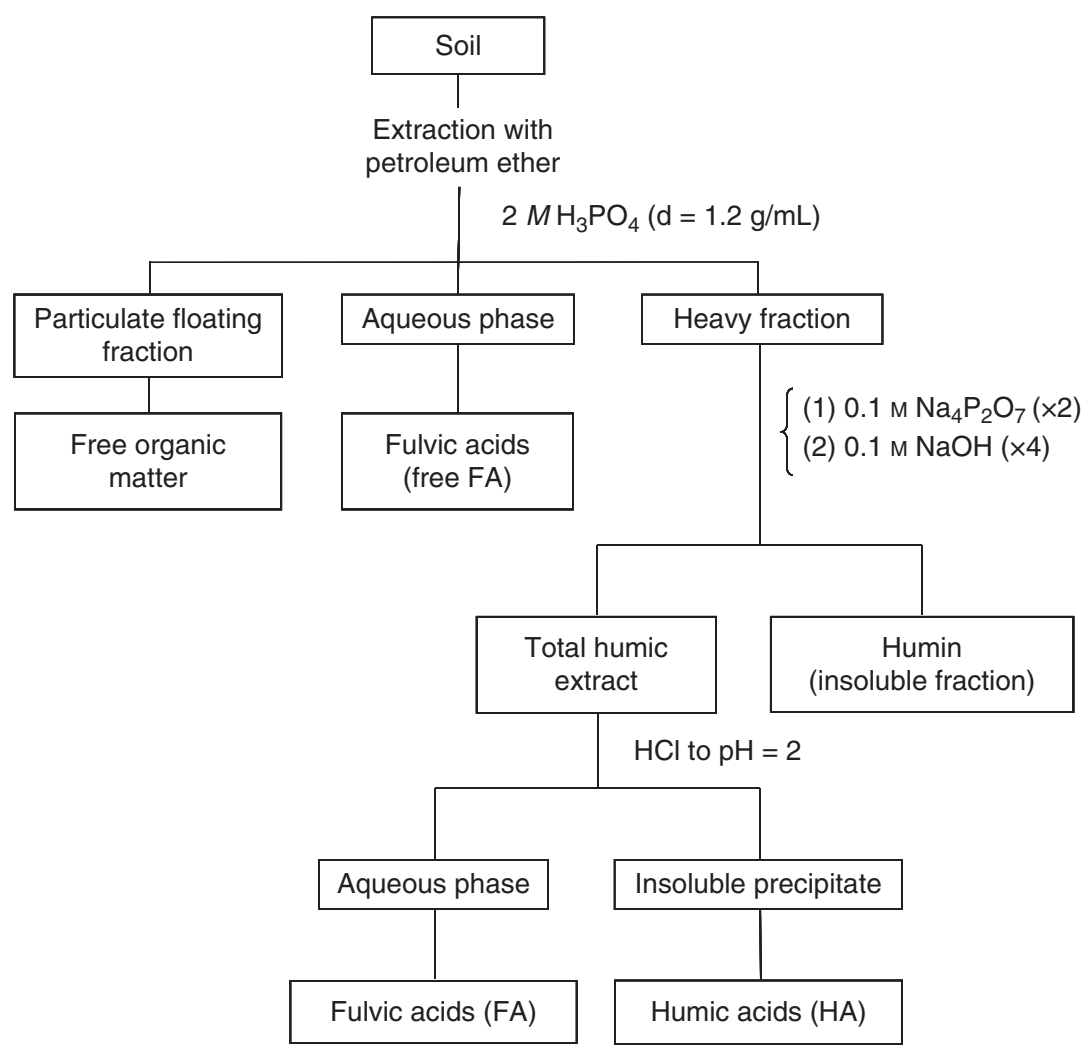

Figure 1 Soil organic matter fractionation procedure. 
matter (FOM) was carried out by flotation using $20 \mathrm{~g}$ soil samples suspended in a $\mathrm{CHBr}_{3}-\mathrm{EtOH}$ mixture $\left(d=1.8 \mathrm{~g} / \mathrm{cm}^{3}\right)$ in $150-\mathrm{cm}^{3}$ centrifuge tubes. The soil suspension was stirred for $1 \mathrm{~min}$ and centrifuged at $3024 \mathrm{~g}$ for $10 \mathrm{~min}$. The light floating particulate fraction was divided into two sub-fractions of different density, by resuspension in $2 \mathrm{~mol} / \mathrm{L} \mathrm{H}_{3} \mathrm{PO}_{4}\left(d=1.25 \mathrm{~g} / \mathrm{cm}^{3}\right)$ and centrifuged at $1935 \mathrm{~g}$ for $5 \mathrm{~min}$. The light floating particulate fraction was labelled as FOM1 $\left(d<1.25 \mathrm{~g} / \mathrm{cm}^{3}\right)$, the heavy particulate fraction as FOM2 $\left(d=1.25-1.8 \mathrm{~g} / \mathrm{cm}^{3}\right)$, and the soluble fraction as free fulvic acid (free FA). The heavy fraction remaining after the first centrifugation with the $\mathrm{CHBr}_{3}-\mathrm{EtOH}$ mixture was subjected to a new $\mathrm{CHBr}_{3}-\mathrm{EtOH}$ treatment to obtain the remaining humin (light fraction). The residue was successively extracted by shaking with $0.1 \mathrm{~mol} / \mathrm{L} \mathrm{Na} \mathrm{N}_{2} \mathrm{O}_{7}$ followed by $0.1 \mathrm{~mol} / \mathrm{L} \mathrm{NaOH}$ (horizontal motion mechanical shaking for $3 \mathrm{~h}$ ) and centrifuged. This treatment was repeated up to five times, and the resulting brown extract obtained corresponded to the total humic content and it was stored in closed bottles $\left(2000 \mathrm{~cm}^{3}\right)$, from which two aliquots were taken. One of the aliquots $\left(25 \mathrm{~cm}^{3}\right)$ was precipitated with $\mathrm{H}_{2} \mathrm{SO}_{4}$ (1:1 by vol.) to determine the acid-insoluble fraction (HA) and, by difference with the total humic extract $\left(25 \mathrm{~cm}^{3}\right)$, the amount of the acidsoluble fraction (FA) was calculated. The soil residue after the alkaline extraction was washed with distilled water and dried at $40{ }^{\circ} \mathrm{C}$. The carbon (C) concentration in this residue was total humin.

\section{Preparative isolation, de-ashing and spectroscopic} characterization of the humic acids

The preparative isolation of the HA fraction was carried out by precipitating the humic extract at pH 2.0 with $6 \mathrm{~mol} / \mathrm{L}$ $\mathrm{HCl}$, then redissolving the precipitate in $250 \mathrm{~cm}^{3}$, low form, Griffin beakers with $0.5 \mathrm{~mol} / \mathrm{L} \mathrm{NaOH}$, followed by centrifugation at $43500 \mathrm{~g}$. The insoluble residue, consisting of particulate mineral and organic fractions, was discarded and the dark brown supernatant solution (sodium humate) was reprecipitated with $6 \mathrm{~mol} / \mathrm{L} \mathrm{HCl}$. The resulting gel was put into cellophane bags (Visking ${ }^{\circledR}$ dialysis tubing, molecular weight cut-off $12000-14000 \mathrm{Da}$; pore diameter ca. $25 \AA$ ) immersed into distilled water for about 1 week, with periodical replacement of the water. After dialysis, the HA was dried at $35^{\circ} \mathrm{C}$. In total, up to 80 variables including the structural units of the HAs were studied using visible and NMR spectroscopies (Stevenson, 1982; Wilson, 1987), perborate degradation (Almendros \& Sanz, 1992), and Curiepoint pyrolysis (Martin, 1975; Saíz-Jiménez \& de Leeuw, 1986; Schnitzer \& Schulten, 1995).

\section{Routine analyses of the humic acids}

Elemental analysis of HAs was performed on a Carlo-Erba NA 1500 Series 2 Elemental Analyzer (CE Elantech,
Lakewood, NJ, USA). Visible spectroscopy was used as a routine tool to assess the aromaticity of the HAs and to obtain information on polydispersity (Traina et al., 1990; Chen et al., 1977). In addition, derivative visible spectroscopy was used to detect chromophors such as microbial metabolites that are incorporated into the HA structure (Kumada \& Hurst, 1967). In order to determine their optical density, HA solutions of $66.6 \mathrm{mg} / \mathrm{L} \mathrm{C}$, that is $50 \%$ diluted compared with the concentration proposed by Kononova (1962) in $0.02 \mathrm{~mol} / \mathrm{L} \mathrm{NaOH}$, were prepared. The secondderivative visible spectra were obtained from the above HA solutions using a Shimadzu UV-240 OP-2 spectrophotometer.

Cross polarization and magic angle spinning (CPMAS) solid-state ${ }^{13} \mathrm{C}$ NMR spectra were obtained at 2.3 Tesla with a Bruker MSL 100 spectrometer at $25.1 \mathrm{MHz}$. Interval between pulses was $3 \mathrm{~s}$ and contact time 1-1.5 ms. For each spectrum between $10^{4}$ and $10^{5}$, free induction decays were accumulated. The line broadening applied was $125 \mathrm{kHz}$ and the filter broadening $25 \mathrm{kHz}$, the acquisition time was $12.3 \mathrm{~ms}$ and the applied spinning speed was $4.3 \mathrm{kHz}$, using one standard, dual-cavity rotor with $300 \mathrm{mg}$ sample. The chemical shifts were calibrated $(0 \mathrm{ppm})$ relative to tetramethylsilane. The integration routine of the spectrometer was used to quantify the relative intensity of the following chemical shift regions: 0-45 ppm (alkyl C), 45-60 ppm (Nalkyl C, methoxyl C), 60-110 ppm (O-alkyl C), 110-160 ppm (aromatic C, olefinic C), 160-185 ppm (carboxyl C, amide C), and 185-245 ppm (ketone C, aldehyde C).

\section{Degradation methods}

Analytical degradation of the HAs was carried out both by wet chemical oxidative degradation with sodium perborate and by thermal degradation (analytical pyrolysis). For perborate degradation, the HAs $(100 \mathrm{mg})$ were heated to $90{ }^{\circ} \mathrm{C}$ in $150-\mathrm{cm}^{3}$ screw-cap Pyrex flasks containing $50 \mathrm{~cm}^{3}$ of $5 \% \quad \mathrm{NaBO}_{2} \cdot \mathrm{H}_{2} \mathrm{O}_{2}$ (Almendros et al., 1987). After $2 \mathrm{~h}$, the brown digest solutions were precipitated with $6 \mathrm{~mol} / \mathrm{L} \mathrm{HCl}$ and the non-degraded residue was separated by centrifugation. One treatment transforms about $40 \%$ of the original weight into soluble products, and the repeated treatments on the above residues allow the total solubilization of the sample without producing a condensed residue, which is the case with other mild degradation methods (Almendros et al., 1987, 1991). Therefore, in our study, perborate treatment was repeated with the residue for up to seven times.

Pyrolysis experiments were carried out using a Curie-point pyrolyzer (Horizon Instruments) attached to a Varian Saturn 2000 GC-MS system. The samples were heated for $5 \mathrm{~s}$ on ferromagnetic wires at $510{ }^{\circ} \mathrm{C}$ Curie-point temperature. The interface temperature was set at $250{ }^{\circ} \mathrm{C}$. The injector, with a liquid $\mathrm{CO}_{2}$ cryogenic unit, was programmed from -30 to $300{ }^{\circ} \mathrm{C}$ at $20^{\circ} \mathrm{C} / \mathrm{min}$. In both cases, the $\mathrm{GC}$ oven was 
adjusted from 50 to $100{ }^{\circ} \mathrm{C}$ at $32^{\circ} \mathrm{C} / \mathrm{min}$ and then up to $320^{\circ} \mathrm{C}$ at a rate of $6{ }^{\circ} \mathrm{C} / \mathrm{min}$. For the chromatographic separation, a fused-silica capillary column $(25 \mathrm{~m} \times 0.32 \mathrm{~mm})$ coated with CPSil (film thickness $0.4 \mu \mathrm{m}$ ) and $\mathrm{He}$ as carrier gas was used. Tentative compound identification was based on literature data and comparisons with mass spectral libraries (National Institute of Standards and Technology (NIST), 1995; Wiley, 2005).

\section{Statistical analysis}

The spatial variability resulting from the different sampling points was analysed by a one-way analysis of variance, using the least significant difference method at the $P<0.05$ level (Fisher, 2006).

\section{Results and discussion}

\section{General analytical characteristics}

Table 2 shows the CEC, exchangeable bases $\left(\mathrm{Na}^{+}, \mathrm{K}^{+}, \mathrm{Ca}^{2+}\right.$ and $\mathrm{Mg}^{2+}$ ), base saturation and CEC:C ratio in the studied soils. A higher value of CEC was observed in the original soils compared with the deforested ones, with values of 41.2

Table 2 Chemical analytical characteristics of the uppermost $(0-$ $10 \mathrm{~cm}$ ) horizon of relictual forests and derived Mediterranean agroecosystems

\begin{tabular}{|c|c|c|c|c|c|}
\hline \multirow[b]{2}{*}{ Characteristic } & \multicolumn{4}{|c|}{ Site $^{\mathrm{a}}$} & \multirow[b]{2}{*}{$\mathrm{LSD}^{\mathrm{b}}$} \\
\hline & $1-\mathrm{OF}$ & $1-\mathrm{CC}$ & $2-\mathrm{AF}$ & 2-PS & \\
\hline $\mathrm{pH}\left(\mathrm{H}_{2} \mathrm{O}\right)$ & 7.9 & 8.4 & 6.8 & 6.0 & 0.1 \\
\hline $\mathrm{CaCO}_{3}(\mathrm{~g} / \mathrm{kg})$ & 68 & 62 & 0 & 0 & 2.0 \\
\hline $\begin{array}{l}\text { Water drop penetration time } \\
(\text { WDPT }, \mathrm{s})\end{array}$ & 29 & 2 & 9 & 2 & 2.3 \\
\hline Water holding capacity $(\mathrm{g} / \mathrm{kg})$ & 881 & 473 & 933 & 699 & 185 \\
\hline Oxidizable $\mathrm{C}(\mathrm{g} / \mathrm{kg})$ & 95.1 & 16.8 & 92.1 & 48.5 & 4.6 \\
\hline Organic matter $(\mathrm{g} / \mathrm{kg})$ & 164 & 29 & 159 & 84 & 7.9 \\
\hline $\mathrm{N}(\mathrm{g} / \mathrm{kg})$ & 6.2 & 1.3 & 7.0 & 3.7 & 0.2 \\
\hline $\mathrm{C}: \mathrm{N}$ & 15.3 & 12.7 & 13.3 & 13.1 & 1.8 \\
\hline $\mathrm{Na}^{+}\left(\mathrm{cmol}_{\mathrm{c}} / \mathrm{kg}\right)$ & 1.13 & 0.52 & 0.43 & 0.35 & 0.56 \\
\hline $\mathrm{K}^{+}\left(\mathrm{cmol}_{\mathrm{c}} / \mathrm{kg}\right)$ & 1.44 & 0.61 & 0.58 & 0.26 & 0.53 \\
\hline $\mathrm{Ca}^{2+}\left(\mathrm{cmol}_{\mathrm{c}} / \mathrm{kg}\right)$ & 34.8 & 19.7 & 17.0 & 8.5 & 4.3 \\
\hline $\mathrm{Mg}^{2+}\left(\mathrm{cmol}_{\mathrm{c}} / \mathrm{kg}\right)$ & 3.8 & 0.42 & 2.8 & 1.1 & 1.2 \\
\hline $\mathrm{H}^{+}\left(\mathrm{cmol}_{\mathrm{c}} / \mathrm{kg}\right)$ & 0 & 0 & 0.99 & 2.39 & 3.66 \\
\hline $\begin{array}{l}\text { Total exchangeable bases } \\
\left(\mathrm{Na}^{+}+\mathrm{K}^{+}+\mathrm{Ca}^{2+}+\mathrm{Mg}^{2+}\right)\end{array}$ & 41.2 & 21.2 & 20.8 & 10.2 & 5.1 \\
\hline $\mathrm{CEC}\left(\mathrm{cmol}_{\mathrm{c}} / \mathrm{kg}\right)$ & 41.2 & 21.2 & 21.8 & 12.6 & 1.8 \\
\hline Base saturation $^{\mathrm{c}}(\%)$ & 100 & 100 & 95 & 81 & 12 \\
\hline CEC:C & 4.3 & 12.6 & 2.4 & 2.6 & 0.4 \\
\hline
\end{tabular}

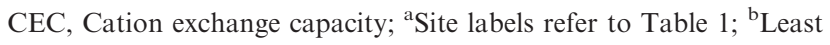
significant difference $(P<0.05)$ calculated from soil composite samples and corresponding to two spatial replications; ${ }^{\mathrm{c}} \mathrm{Base}$ saturation $=($ Total exchangeable bases $/$ CEC $) \times 100$. and $21.2 \mathrm{cmol}_{\mathrm{c}} / \mathrm{kg}$ for $1-\mathrm{OF}$ and $1-\mathrm{CC}$, and of 21.8 and $12.6 \mathrm{cmol}_{\mathrm{c}} / \mathrm{kg}$ for 2-AF and 2-PS, respectively. These differences were more significant when the clay content was comparatively higher, as in soil 1-CC. Nevertheless, the soil textural types did not change (Table 1). As expected, the SOM content decreased in deforested soils compared with the corresponding wooded area (16 and 3\% for $1-\mathrm{OF}$ and $1-\mathrm{CC}$, and 16 and $8 \%$ for 2-AF and 2-PS). The CEC:C ratio, used as an index of soil quality, remained unchanged between 2$\mathrm{AF}$ and 2-PS (2.4 and 2.6, respectively), but increased significantly from 1-OF to 1-CC (4.3-12.6).

The CEC:C ratio could be regarded as an index of the quality of humus, considering that SOM accounts for most $(>70 \%)$ of the soil exchange capacity (Stevenson, 1982). In fact, the soil CEC usually displays values parallel to those of soil C (Skyers et al., 1970; Rashidi \& Seilsepour, 2008). Although mainly used for the assessment of composts quality (Hachicha et al., 2009; Kianirad et al., 2009) a high CEC:C ratio could be considered a good indicator of well-humified SOM, as opposed to the less evolved types of humus, where the contribution to the CEC by $\mathrm{C}$ unit is much less (GarcíaGómez et al., 2005; Melo et al., 2007). This index should be especially useful for cultivated soils, where the classical $\mathrm{C}: \mathrm{N}$ ratio usually used to estimate humus quality is not biased by fertilization. The former case was observed in 1-CC compared with 1-OF, suggesting a higher level of oxidation of SOM as a result of the effect of mechanical tillage, whereas the effect of grazing at 2-PS compared with 2-AF did not show significant differences. The decrease in the SOM concentration in deforested soils (16 and 3\% for $1-\mathrm{OF}$ and $1-\mathrm{CC}$, and 16 and $8 \%$ for 2-AF and 2-PS) agrees with the above statements, and could be attributed to the accelerated mineralization induced by tillage.

\section{Free lipid fraction}

Total abundances and ratios between the different groups of fatty acids, alkanes, alcohols and terpenic compounds identified in the lipid fraction are presented in Table 3. It was observed that deforestation of the forest led to some decrease in the total amount of non-polar constituents (alkanes), whereas changes in the amount of fatty acids were comparatively small. The total concentration of alcohols tended to increase both in pastured and cultivated sites. Concerning chain length, both in the cases of alkanes and fatty acids, some significant trend to short chain length in deforested sites was observed. Diagnostic changes in the terpenic compounds were evident: in forest soil 2-AF, a series of hydrocarbons and diterpene resin acids (dehydroabietin, totarol methylether, dehydroabietal and pimaric acid) prevailed, whereas in deforested site 2-PS triterpenoids accounted for $2.1-3.9 \%$ of the total volatile compounds (Figure 2). This group includes the sterols, which in 2-PS were represented by cholesterol, ergost-5-in-3 $\beta$-ol and 
Table 3 Total yield of soil lipids ${ }^{\mathrm{a}}$, and total abundances ${ }^{\mathrm{b}}$ and ratios between the different groups of their fatty acids, alkanes, alcohols and terpenic compounds in soils under forests and cleared Mediterranean ecosystems

\begin{tabular}{|c|c|c|c|c|c|}
\hline \multirow[b]{2}{*}{ Compounds } & \multicolumn{4}{|c|}{ Site $^{\mathrm{c}}$} & \multirow[b]{2}{*}{$\operatorname{LSD}^{\mathrm{d}}$} \\
\hline & $1-\mathrm{OF}$ & $1-\mathrm{CC}$ & $2-\mathrm{AF}$ & 2-PS & \\
\hline Total yields of soil lipids & 0.04 & 0.01 & 0.07 & 0.03 & \\
\hline Total fatty acids & 14.8 & 10.8 & 36.5 & 35.6 & 7.4 \\
\hline Total $n$-fatty acids & 10.5 & 10.5 & 33.8 & 30.4 & 9.6 \\
\hline Linear:branched fatty acids & 2 & 35 & 44 & 16 & 4 \\
\hline Total non-saturated fatty acids & - & - & 1.9 & 3.1 & 0.3 \\
\hline $2 n: 2 n+1$ fatty acids & 4.0 & 3.0 & 5.0 & 3.0 & 0.5 \\
\hline$>\mathrm{C}_{20}:<\mathrm{C}_{20}$ fatty acids & 1.0 & 1.0 & 5.0 & 3.0 & 0.8 \\
\hline Total alkanes & 47.3 & 33.8 & 38.8 & 21.9 & 5.8 \\
\hline Lineal:branched alkanes & - & 187 & - & 4 & 15 \\
\hline $2 n: 2 n+1$ alkanes & 7 & 6 & 12 & 4 & 1 \\
\hline$>\mathrm{C}_{20}:<\mathrm{C}_{20}$ alkanes & 214 & 167 & 241 & 49 & 26 \\
\hline Total alcohols & 33.6 & 53.5 & 22.8 & 36.5 & 1.7 \\
\hline Total $n$-alcohols & 32.7 & 50.8 & 18.5 & 28.0 & 3.7 \\
\hline Total branched alcohols & 0.9 & 2.7 & 4.3 & 8.5 & 1.2 \\
\hline Linear:branched alcohols & 37 & 19 & 4 & 3 & 0.4 \\
\hline Total diterpenoids & 0.0 & 0.0 & 0.9 & 0.3 & 0.02 \\
\hline Total triterpenoids & 0.0 & 0.0 & 0.3 & 3.5 & 0.7 \\
\hline Total abietanes & 0.0 & 0.0 & 0.8 & 0.0 & 0.1 \\
\hline Total pimaranes & 0.0 & 0.0 & 0.1 & 0.3 & 0.1 \\
\hline Total cyclics & 0.0 & 0.0 & 1.2 & 3.8 & 0.1 \\
\hline Total aromatics & 0.0 & 0.0 & 0.8 & 0.0 & 0.01 \\
\hline
\end{tabular}

${ }^{\mathrm{a}}$ Expressed as g of $\mathrm{C} / \mathrm{kg}$ soil; ${ }^{\mathrm{b}}$ Percentage of the total volatile compounds in the methylated lipid sample. Chromatographic peaks representing $<0.01 \%$ of total volatile products were not taken into account (symbolized as - ); ${ }^{\mathrm{c}}$ Site labels refer to Table I; ${ }^{\mathrm{d}}$ Least significant difference $(P<0.05)$.

$\beta$-stigmasterol, all of them characterized by the molecular ion $\left(\mathbf{M}^{+}\right), \mathbf{M}^{+}-15, \mathbf{M}^{+}-(15+18), \mathbf{M}^{+}-70$ and the $m / z$ $271,255,246,231$ and 213 ions, that are common to the three spectra (Knights, 1967). Other triterpenoids identified have pentacyclic skeleton, in particular, friedolean-14-in-3one $\left(m / z\right.$ 133, 204, 300 and $\mathbf{M}^{+}$424) was found. Pimaric acid occurred as traces in samples 2-AF and 2-PS.

The analysis of the series of alkyl homologues (not shown) suggested enhanced microbial activity after deforestation (Moucawi et al., 1981), as it could correspond to the removal of slowly biodegradable woody vegetation. The small amounts of cyclic diterpene compounds in 2-AF and 2-PS, which are typical constituents of resins in higher plants (Gough, 1964), could be explained from the relictual vegetation or from aerosols released by neighbouring pine forests. The pimaran-type diterpenoids, which are less stable than the abietanes, were found in smaller proportions. Triterpenoids, only found in 2-PS, mainly consisted of steroidal compounds, that is tetracyclic alcohols of 27, 28 or $29 \mathrm{C}$ atoms by molecule, from animal origin (Puglisi et al.,
2003). Also, triterpenoids with pentacyclic skeleton, widely distributed in higher plants as constituents of epicuticular waxes (Walton, 1990) accumulated in 2-PS. In particular, a possible root-derived triterpenoid with friedelan-14-en-3-one structure (Naafs, 2004) was detected.

\section{Macromolecular soil organic matter fractions}

Figure 3 shows the percentage of the different organic fractions isolated from the soils (Duchaufour \& Jacquin, 1975): free lipids, FOM1, FOM2, inherited humin (Chouliaras et al., 1975), free FA, HA, FA and humin. The FOM1 varied between 3 and $38 \%$ of total soil $\mathrm{C}$, whereas FOM2 was between 7 and $74 \%$. Both the C content of FOM1 and FOM2 decreased from forests (1-OF and 2-AF) to deforested areas (1-CC and 2-PS), whereas the SOM heavy fraction (HAs, fulvic acids and humin) showed the opposite trend. Physical protection of particulate OM in deforested soils is suggested by the values of inherited humin in 2-PS soil. This fraction was previously suggested by Nierop et al. (2001) as a source of information on humus variability between grassland and arable soils. In fact, Skjemstad et al. (2008), in a deforested Oxisol that has been under continuous pasture for $90 \mathrm{yr}$, found that physical protection in microaggregates was one of the major mechanisms of SOM protection.

A preferential accumulation of comparatively stable SOM (HAs, FAs and humin, Figure 3) was observed in the deforested areas compared with the original forests. In fact, the relative amount of these more stable SOM fractions represented less than $20 \%$ of total soil $\mathrm{C}$ in soils from the original oak forests (17.2 and $15.1 \%$ in $1-\mathrm{OF}$ and $2-\mathrm{AF}$, respectively), and more than $60 \%$ of total soil $\mathrm{C}$ in soils from the deforested sites (83.0 and $60.9 \%$ in 1-CC and 2-PS, respectively). The $\mathrm{C}$ content of the stable fractions (FAs + HAs + humin) in the soil ( $\mathrm{g} \mathrm{C}$ of the fractions per $100 \mathrm{~g}$ soil), were fairly constant between 1-OF and 1-CC (1.63 and $1.39 \mathrm{~g} \mathrm{C}$ per $100 \mathrm{~g}$ soil, respectively), despite the decrease in soil $\mathrm{C}$ content from $9.51 \%$ in 1 -OF to $1.68 \%$ in $1-$ CC. In the case of soils 2-AF and 2-PS, the C content of the stable fractions in the soil increased after conversion of the original oak forest to pasture, from $1.39 \mathrm{~g} \mathrm{C}$ per $100 \mathrm{~g}$ soil in 2-AF to $2.95 \mathrm{~g} \mathrm{C}$ per $100 \mathrm{~g}$ soil in 2-PS. In these soils, the decrease in soil $\mathrm{C}$ content was less marked than in soils 1-OF and 1 -CC, with $9.21 \%$ in 2 -AF and $4.85 \%$ in 2 -PS.

These observations indicate that tillage and/or grazing, in combination with the change of vegetation from woody to herbaceous, would imply a greater biodegradability of the plant residues and a greater proportion of humified fractions (Nierop et al., 2001). This is in agreement with the results of Grünzweig et al. (2004), which studied the dynamics of soil C stocks after conversion of forest soils to agriculture. These authors observed a loss of soil $\mathrm{C}$ during the first $20 \mathrm{yr}$ after deforestation, attributed to combustion of cleared forest biomass, decomposition of organic matter and probably 

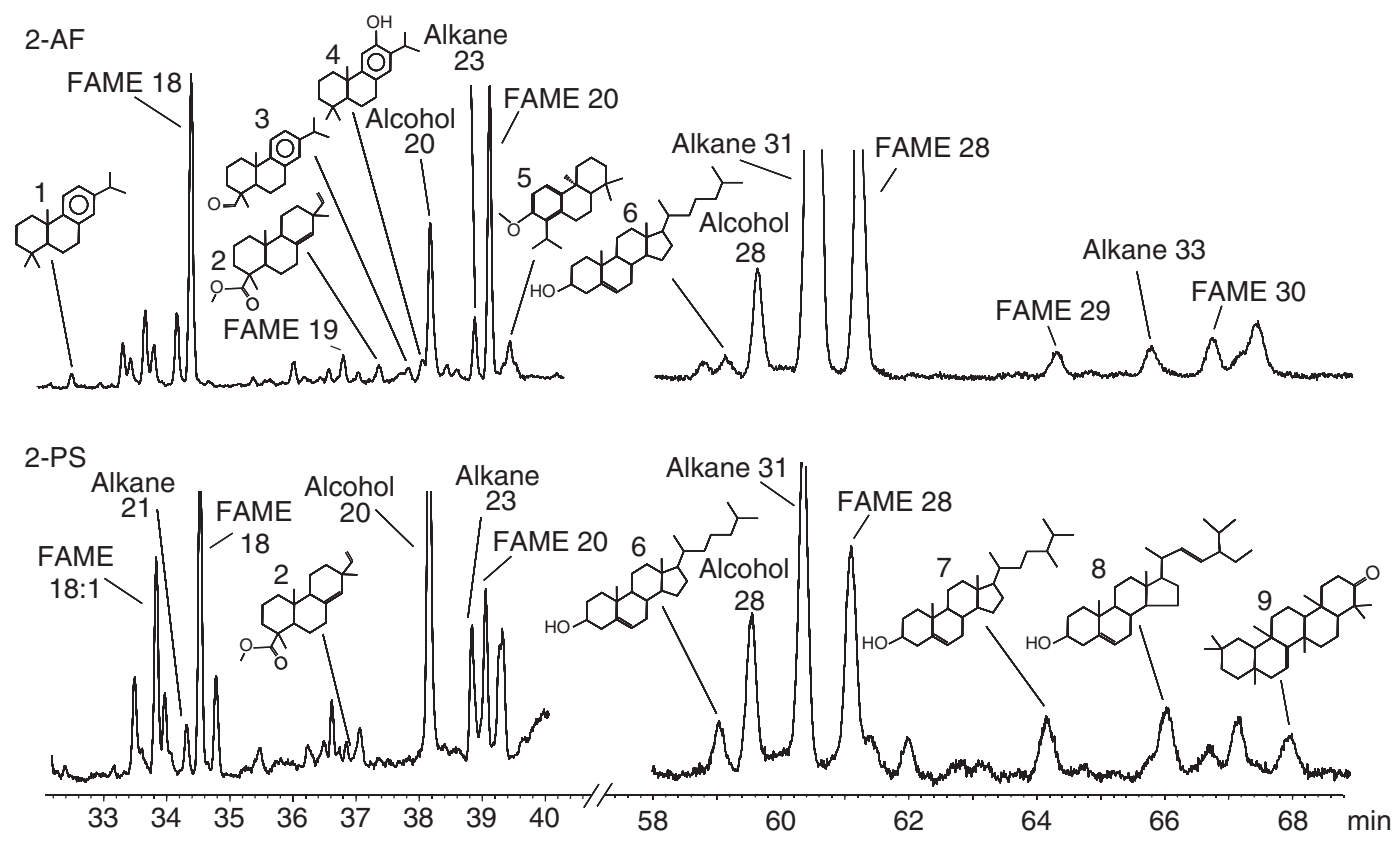

Figure 2 Main terpenic compounds identified in soil lipid fraction chromatograms obtained by Pyrolysis-GC-MS of humic acids. 2-AF, ash forest; 2-PS, deforested neighbouring pasture; 1, dehydroabietane; 2, methyl pimarate; 3, dehydroabietal; 4, ferruginol; 5, totarol methylether; 6 , cholesterol (cholest-5-en-3 $\beta$-ol); 7, ergost-5-en-3 $\beta$-ol (24 $\beta$-methylcholesterol); $8, \beta$-stigmasterol (stigmasta-5,22-dien-3 $\beta$-ol); $9, D$-friedelan-14-en-3one; FAME 18, Fatty Acid Methyl Ester, octadecanoic acid; FAME 18:1, Fatty Acid Methyl Ester, octadecenoic acid; FAME 19, Fatty Acid Methyl Ester, nonadecanoic acid; FAME 20, Fatty Acid Methyl Ester, eicosanoic acid; FAME 28, Fatty Acid Methyl Ester, octacosanoic acid; FAME 29, Fatty Acid Methyl Ester, nonacosanoic acid.

erosion. However, after this period, an increase in soil $\mathrm{C}$ stocks was observed, this effect was attributed to the lowtillage frequency, large $\mathrm{C}$ inputs from belowground biomass

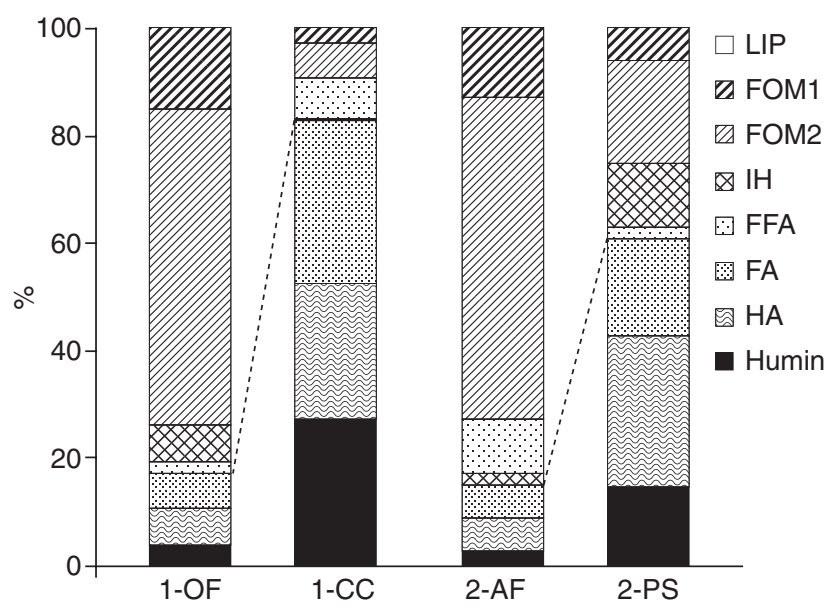

Figure 3 Distribution of total carbon in the different soil organic fractions ( $\% \mathrm{C}$ respect to total soil $\mathrm{C})$. 1-OF, seminatural evergreen oak forest; 1-CC, deforested evergreen oak forest used for cereal cultivation; 2-AF, ash forest; 2-PS, deforested neighbouring pasture; FOM1, free organic matter with density $<1.2 \mathrm{~g} / \mathrm{cm}^{3}$; FOM2, free organic matter with density $1.2-1.8 \mathrm{~g} / \mathrm{cm}^{3}$; $\mathrm{IH}$, inherited humin; FFA, free fulvic acid; FA, fulvic acid; HA, humic acid. of herbaceous vegetation and low $\mathrm{C}$ losses because of small $\mathrm{C}$ stocks in the original forest soils. In our work, under comparatively dryer climatic conditions, even when conversion from forest to agriculture has been carried out more than $30 \mathrm{yr}$ ago, no increase in soil $\mathrm{C}$ storage was observed. In fact, Hutchinson et al. (2007) indicated that C losses and gains because of anthropic activity are strongly dependant on the specific climatic, edaphic and management conditions of the region. These authors mainly differentiate between temperate and tropical areas, indicating management strategies to improve $\mathrm{C}$ storage in soils. In temperate regions, reduced bare fallow, as well as tillage intensity and frequency, increased use of forages in crop rotations, better crop residue management and agroforestry adoption are the recommended alternatives, whereas in the tropics agroforestry is the primary method suggested. Thus, and as it is observed in our results, conversion from forest to pasture (2-PS vs. 2-AF) would be more favourable to $\mathrm{C}$ sequestration than conversion to crops involving periodical tillage (1-CC vs. 1-OF, in our study).

\section{Routine analyses of the humic acids}

In Table 4, data of the elemental analysis of HAs and the visible spectroscopy indices are presented. The $\mathrm{H}: \mathrm{C}$ and $\mathrm{O}: \mathrm{C}$ ratios were lower in 1-CC than in 1-OF (HAs from oak 
forest), indicating a more advanced humification stage. The E4:E6 ratio was smaller in HAs in cultivated soil (1-CC) than in oak forest (1-OF), probably reflecting a high degree of condensation of the aromatic domain, which coincided with the results obtained by elemental analysis. This coincides with the results of Schnitzer et al. (2006), who described enhanced aromaticity in soils as a result of long-term cultivation. The spectroscopic analyses of the HAs also showed increased aromaticity after deforestation (reflected in the E4 value) and concentration of fungal quinoid pigments (particularly evidenced in the $620 \mathrm{~nm}$ peak).

In Table 5, the signal intensity values and ratios between groups of compounds of the CPMAS ${ }^{13} \mathrm{C}$ NMR spectra of the HAs are presented. The ${ }^{13} \mathrm{C}$ NMR spectra confirmed that HAs from soil under crop (1-CC) had greater oxidation (160$220 \mathrm{ppm})$ and aromaticity $(110-160 \mathrm{ppm})$ than in the control oak forest (1-OF).

The atomic $\mathrm{H}: \mathrm{C}$ ratio, inversely related to the aromaticity, suggests that in deforested soils an intense maturation of the HAs takes place, this would correspond to an acceleration of the biogeochemical cycle. The visible spectroscopy yields additional data on degree of condensation and aromaticity (Stevenson, 1982). It has been observed that the optical density of humic substances tends to increase during the

Table 4 Elemental composition (ash-free), ratios between the concentration of the different elements and visible spectroscopy values of humic acids from soils under relictual forests and derived agroecosystems

\begin{tabular}{|c|c|c|c|c|c|}
\hline & \multicolumn{4}{|c|}{ Site $^{\mathrm{a}}$} & \multirow[b]{2}{*}{$\mathrm{LSD}^{\mathrm{b}}$} \\
\hline & $1-\mathrm{OF}$ & $1-\mathrm{CC}$ & $2-\mathrm{AF}$ & 2-PS & \\
\hline \multicolumn{6}{|c|}{ Elemental analysis } \\
\hline $\mathrm{C}(\mathrm{g} / \mathrm{kg})$ & 530 & 544 & 541 & 531 & 5.0 \\
\hline $\mathrm{H}(\mathrm{g} / \mathrm{kg})$ & 55 & 53 & 65 & 61 & 6.0 \\
\hline $\mathrm{N}(\mathrm{g} / \mathrm{kg})$ & 37 & 45 & 44 & 41 & 1.0 \\
\hline $\mathrm{O}(\mathrm{g} / \mathrm{kg})$ & 377 & 359 & 351 & 368 & 8.0 \\
\hline $\mathrm{C}: \mathrm{N}$ & 14.3 & 12.1 & 12.4 & 12.9 & 0.04 \\
\hline Atomic $\mathrm{H}: \mathrm{C}$ & 1.23 & 1.18 & 1.43 & 1.37 & 0.01 \\
\hline Atomic O:C & 0.53 & 0.49 & 0.49 & 0.52 & 0.0 \\
\hline \multicolumn{6}{|c|}{ Visible spectroscopy (absorption units) $^{c}$} \\
\hline E4 & 1.09 & 1.97 & 0.76 & 1.00 & 0.06 \\
\hline E4:E6 & 6.03 & 4.16 & 4.95 & 4.66 & 0.52 \\
\hline \multicolumn{6}{|c|}{$\begin{array}{l}\text { Intensities of the valleys in the second derivative of the spectra } \\
\text { (absorption units) }^{\mathrm{d}}\end{array}$} \\
\hline $455 \mathrm{~nm}$ & 0.006 & 0.015 & 0.009 & 0.019 & 0.003 \\
\hline $530 \mathrm{~nm}$ & 0.009 & 0.015 & 0.007 & 0.008 & 0.005 \\
\hline $570 \mathrm{~nm}$ & 0.007 & 0.013 & 0.006 & 0.009 & 0.003 \\
\hline $620 \mathrm{~nm}$ & 0.009 & 0.014 & 0.008 & 0.014 & 0.003 \\
\hline
\end{tabular}

${ }^{\text {a }}$ Site labels refer to Table 1 ; ${ }^{b}$ Least significant difference $(P<0.05)$; ${ }^{\mathrm{c}} \mathrm{E} 4=$ extinction at $465 \mathrm{~nm}\left[0.2 \mathrm{mg}\right.$ of carbon per $\left.\mathrm{cm}^{3}\right]$, E4:E6 = ratio of extinction at $465-665 \mathrm{~nm}$; ${ }^{\mathrm{d}}$ Obtained using $0.1 \mathrm{mg}$ of carbon per $\mathrm{cm}^{3}$ humic acids solutions.
Table 5 Relative amounts (\%) of total signal intensity and ratios between spectral areas for the main regions of the ${ }^{13} \mathrm{C}$ NMR spectra of humic acids from soils under relictual forests and derived Mediterranean agroecosystems

\begin{tabular}{lrrrrr}
\hline & \multicolumn{5}{c}{ Site $^{\mathrm{a}}$} \\
\cline { 2 - 5 } & 1-OF & 1-CC & 2-AF & 2-PS & LSD $^{\mathrm{b}}$ \\
\cline { 2 - 5 } & 25.3 & 22.2 & 30.1 & 27.7 & 4.8 \\
Alkyl region (0-46 ppm) & 39.3 & 35.7 & 38.7 & 42.8 & 4.3 \\
O-alkyl region (46-110 ppm) & 24.3 & 29.5 & 21.1 & 20.7 & 3.2 \\
Aromatic region (110-160 ppm) & 1.2 & 12.6 & 10.1 & 8.8 & 1.3 \\
Carbonyl region (160-220 ppm) & 11.3 & & & & \\
Ratios & 1.0 & 0.8 & 1.4 & 1.3 & 0.4 \\
$\quad$ Alkyl:Aromatic & 1.6 & 1.6 & 1.3 & 1.5 & 0.1 \\
O-Alkyl:Alkyl & 1.6 & 1.2 & 1.8 & 2.1 & 0.2 \\
O-Alkyl:Aromatic & 0.5 & 0.4 & 0.5 & 0.4 & 0.03 \\
Carbonyl:Aromatic & & & & & \\
\hline
\end{tabular}

$\overline{{ }^{a} \text { Site labels refer to Table } 1 \text {; }{ }^{b} \text { Least significant difference }(P<0.05)}$.

humification process and degree of aromaticity (Kononova, 1982; Traina et al., 1990). Hence, some trend to higher E4 intensity, as well as a decrease in the E4:E6 ratio, would suggest an increase in both the aromaticity (Traina et al., 1990) and the molecular size (Chen et al., 1977), which could be an effect of progressive humification of SOM. The increased values of $\mathrm{E} 4$ in both deforested sites are in agreement with the results of the atomic ratios, and suggest accumulation of HA with increased maturity; this could also correspond to preferential biodegradation of the aliphatic domain. Also, the ${ }^{13} \mathrm{C}$ NMR spectra confirmed aromatic enhancement in deforested soils (1-OF and 1-CC), in agreement with Nascimento et al. (1992). Similar results were obtained by Quénéa et al. (2006), who reported an increase in the accumulation of the refractory organic macromolecular fraction in deforested soils under continuous maize crop, partly as a result of selective elimination of aliphatic constituents of plant biomass probably induced by agricultural use.

\section{Degradation methods}

Up to 92 major compounds (i.e. those representing at least $0.01 \%$ of the total ion chromatographic area) were identified after the perborate degradation (Table 6), their relative yields showing large amounts of $\alpha, \omega$-alkanedioic acids and fatty acids.

Alkanes were missing and aliphatics represented more than a third of the total degradation compounds. The aromatic series included major fractions of phenolic and benzenecarboxylic acids, amounting to up to $60 \%$ of the total degradation products in 1-CC, where the highest value was observed. The benzenecarboxylic:phenolic ratio increased after deforestation from 0.5 (1-OF and 2-AF) to 0.7 (1-CC and 2-PS), indicating progressive oxidation of aromatics. 
Table 6 Total abundances ${ }^{\mathrm{a}}$ and ratios between different groups of $\mathrm{NaBO}_{3}$-degradation products of humic acids

\begin{tabular}{lrrrrl}
\hline & \multicolumn{5}{c}{ Site $^{\mathrm{b}}$} \\
\cline { 2 - 5 } & & & \\
Compounds & 8.6 & 12.5 & 10.2 & 7.3 & 1.5 \\
\hline \multirow{2}{*}{ Total fatty acids } & 18.6 & 12.6 & 25.2 & 26.8 & 7.8 \\
Total $n$ - $\alpha, \omega$-alkanedioic acids & 21.7 & 15.0 & 29.4 & 30.2 & 3.0 \\
Total $\alpha, \omega$-alkanedioic acids & 25.9 & 31.5 & 24.7 & 25.2 & 4.3 \\
Total phenolic acids & 13.1 & 21.8 & 13.0 & 17.0 & 1.7 \\
Total benzenecarboxylic acids & 45.8 & 60.3 & 46.4 & 49.6 & 7.6 \\
Total aromatics & 36.8 & 31.4 & 45.7 & 44.1 & 6.6 \\
Total aliphatics & 0.5 & 0.7 & 0.5 & 0.7 & 0.2 \\
Benzenecarboxylic:phenolic & 0.8 & 0.5 & 1.0 & 0.9 & 0.08 \\
Aliphatic:aromatic & 1.4 & 1.0 & 1.9 & 1.8 & 0.2 \\
Aliphatic:phenolic & 2.8 & 1.4 & 3.5 & 2.6 & 0.2 \\
Aliphatic:benzenecarboxylic & 0.4 & 0.8 & 0.3 & 0.2 & 0.04 \\
Fatty acids: $\alpha, \omega$-alkanedioic acids & 1.5 & 2.0 & 2.9 & 1.5 & 0.4 \\
Syringil compounds & 12.5 & 9.9 & 11.4 & 12.1 & 1.2 \\
Guaiacyl compounds & 0.1 & 0.2 & 0.3 & 0.1 & 0.02 \\
Syringil:Guaiacyl & & & & \\
\hline
\end{tabular}

${ }^{\text {a Percentages of the total volatile methylated degradation products of }}$ the HAs. Chromatographic peaks representing $<0.01 \%$ of total

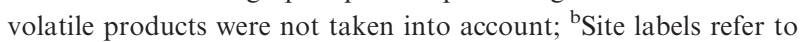
Table 1; ${ }^{c}$ Least significant difference $(P<0.05)$.

The analysis of the series of alkyl homologues suggested the breakdown of hydroxyacid constituents of plant aliphatic biomacromolecules, such as cutins and suberins (Almendros \& Sanz, 1991). The significant increase in the deforested soils of the benzenecarboxylic:phenolic ratio could be interpreted as active oxidation of lignins, with the higher aromaticity being observed in 1-CC. In the case of the oak forest transformed into cereal crop (1-CC), the amount of alkyl compounds changed significantly; the relative abundances of $\alpha, \omega$-alkanedioic acids decreased and that of fatty acid increased.

\section{Pyrolysis-GC/MS study}

The main pyrolysis products from the HAs were methoxyphenols (5.2-19.2\%, Table 7) with characteristic substitutions indicating a lignin origin. Other pyrolysis products were alkylbenzenes, phenols, alkylphenols, $n$ alkanes, $n$-alkenes, fatty acids and steroids. A conspicuous series of $\mathrm{C}_{3}-\mathrm{C}_{6}$ alkylbenzenes was predominant. Indene, $\mathrm{C}_{1^{-}}$ $\mathrm{C}_{3}$ alkylindenes, naphthalene and $\mathrm{C}_{1}-\mathrm{C}_{3}$ alkylnaphthalenes were also present in the pyrolysates. In addition to fatty acids of linear chain, the presence of iso- and anteiso-pentadecanoic acids and oleic acid has been recognized.

As opposed to perborate degradation, pyrolysis is not suitable to detect changes in the carboxyl content, as it produces decarboxylation and does not yield benzenecarboxylic acids. Nevertheless, pyrolysis is considered to be a technique highly responsive to the substitution
Table 7 Total abundances ${ }^{\mathrm{a}}$ of the different groups of compounds identified by analytical pyrolysis from soils under relictual forests and derived Mediterranean agroecosystems

\begin{tabular}{lrrrrr}
\hline & \multicolumn{5}{c}{ Site $^{\mathrm{b}}$} \\
\cline { 2 - 5 } & 1-OF & 1-CC & 2-AF & 2-PS & LSD $^{\mathrm{c}}$ \\
\cline { 2 - 5 } Compounds & 22.3 & 7.1 & 19.9 & 15.7 & 2.0 \\
Total phenols & 9.1 & 3.2 & 18.1 & 2.7 & 2.8 \\
Total alkylbenzenes & 1.4 & 0.2 & 0.5 & 0.6 & 0.1 \\
Total naphthalenes & 1.2 & 0.4 & 0.4 & 0.7 & 0.1 \\
Total indenes & 12.2 & 4.0 & 9.5 & 8.7 & 0.8 \\
Total guaiacyl compounds & 7.4 & 1.2 & 5.3 & 4.3 & 0.6 \\
Total syringyl compounds & 19.2 & 5.2 & 14.1 & 12.4 & 1.1 \\
Total methoxyphenols & 0.0 & 0.0 & 0.0 & 0.2 & 0.04 \\
Total steroids & 2.6 & 1.0 & 3.0 & 5.1 & 0.9 \\
Total alkanes & 2.1 & 0.7 & 3.3 & 2.9 & 0.3 \\
Total alkenes & 4.7 & 1.2 & 3.9 & 6.7 & 0.7 \\
Total fatty acids & & & & & \\
\hline
\end{tabular}

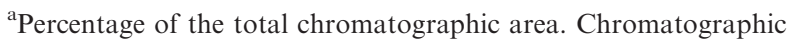
peaks representing $<0.01 \%$ of total volatile products were not taken into account; ${ }^{\mathrm{b}}$ Site labels refer to Table 1 ; ${ }^{\mathrm{c}}$ Least significant difference $(P<0.05)$.

patterns in lignin units (Martin et al., 1979). In addition, all pyrograms presented a series of doublets of $n$-alkanes and alkenes, confirming the high aliphatic character of the HAs found in the ${ }^{13} \mathrm{C}$ NMR analysis. In some cases, it has been proposed that the origin of this aliphatic domain in HAs is from new macromolecules, non-saponificable and highly aliphatic, mainly from plant cuticles (Nip et al., 1986; de Leeuw \& Largeau, 1993). These macromolecules would display pyrograms characterized by a series of alkanes and alkenes (Saíz-Jiménez \& de Leeuw, 1986, 1987; Augris et al., 1998), their contribution to the structure of humic substances being proposed by Tegelaar et al. (1989) and Kögel-Knabner et al. (1992). Pyrolysis results also coincide with those from perborate degradation as regards the decreased yields of lignin-derived methoxyphenols in deforested soils.

\section{Conclusions}

Perborate degradation provides information on the amounts of the different $\mathrm{C}$ forms accumulated in soils in the long term, whereas free soil lipid fractions included signature compounds suggesting changes in organisms and processes after deforestation (Jandl et al., 2007). Perborate degradation yielded large amounts of alkyl compounds with chain lengths suggesting an origin from unsaturated lipid material or hydroxyacid constituents of cutins and suberins characteristic of underground plant biomass prevalent in grassland soil. This technique is especially useful for detecting the extent of oxidation through the yield of benzenecarboxylic acids. On the other hand, analytical pyrolysis supplies the specific information on changes in demethoxylation of lignin-derived 
structures after deforestation, which helps us to understand the biogeochemical enhancement induced by the removal of the original forest, which not only leads to decreased SOM levels but to increased diagenetic transformation of plant biomacromolecules. This coincides with the results from classical wet chemical fractionation, which suggested increased organo-mineral interaction and an enhancement in the amount of macromolecular humic fractions, as well as a concomitant relative decrease in the particulate, fairly welldecomposed SOM fractions. Qualitative changes in free lipid assemblages were also observed in the cyclic structures; whereas in 2-AF forest soil, there was a series of hydrocarbons and diterpene resin acids inherited from woody plants, the probable origin of most of the SOM in pastured soil 2-PS was shown by typical signature lipids of animal origin and from underground plant biomass, which is a major source of organic matter in rhizogenic humus under grassland. The generally reduced chain length of the alkane molecules suggest that these changes could be attributed to an enhancement of microbial activity. Structural inferences based on molecular proxies could benefit from the use of nondestructive or mild degradation methods $\left(\mathrm{NaBO}_{2} \cdot \mathrm{H}_{2} \mathrm{O}_{2}\right)$ that minimize the breakdown of aliphatic structures. This could be used to assess recent environmental impacts associated with changes in land use and management. In particular, the present multi-analytical approach helps us understand the changes in quality and quantity of SOM after forest clearing.

\section{Acknowledgements}

The authors thank the Spanish Ministry of Science and Innovation (MICINN) for the Project CGL2008-04296/BTE. Dr. Ana Piedra Buena was contracted under the I3P Program at CCMA-CSIC, with financial support from European Social Fund.

\section{References}

Almendros, G. \& Sanz, J. 1991. Structural study on the soil humin fraction-Boron trifluoride-methanol transesterification of soil humin preparations. Soil Biology \& Biochemistry, 23, 1147-1154.

Almendros, G. \& Sanz, J. 1992. A structural study of alkyl polymers in soil after perborate degradation of humin. Geoderma, 53, 79-95.

Almendros, G., Martín, F. \& González-Vila, F.J. 1987. Depolymerization and degradation of humic acids with sodium perborate. Geoderma, 39, 235-247.

Almendros, G., Sanz, J., González-Vila, F.J. \& Martin, F. 1991. Evidence for a polyalkyl nature of soil humin. Naturwissenschaften, 78, 359-362.

Apezteguía, H.P., Izaurralde, R.C. \& Sereno, R. 2009. Simulation study of soil organic matter dynamics as affected by land use and agricultural practices in semiarid Córdoba, Argentina. Soil \& Tillage Research, 102, 101-108.

Augris, N., Balesdent, J., Mariotti, A., Derenne, S. \& Largeau, C. 1998. Structure and origin of insoluble and non-hydrolyzable, aliphatic organic matter in a forest soil. Organic Geochemistry, $\mathbf{2 8}$, 119-124.

Bertoncini, E.I., D’Orazio, V., Senesi, N. \& Mattiazzo, M.E. 2008. Effects of sewage sludge amendment on the properties of two Brazilian oxisols and their humic acids. Bioresource Technology, 99, 4972-4979.

Cerri, C.C., Volkoff, B. \& Andreaux, F. 1991. Nature and behaviour of organic matter in soils under natural forest, and after deforestation, burning and cultivation, near Manaus. Forest Ecology \& Management, 38, 247-257.

Chen, Y., Senesi, N. \& Schnitzer, M. 1977. Information provided on humic substances by $\mathrm{E}_{4} / \mathrm{E}_{6}$ ratios. Soil Science Society of America Journal, 41, 352-358.

Chouliaras, N., Vedy, J.C., Jacquin, F. \& Portal, J.M. 1975. Fractionnement et caractérisation de la matière organique dans les Rendzines. Bulletin Ecole Nationale Supérieure d'Agronomie et des Industries Alimentaires, 17, 65-74.

Dabin, B. 1971. Étude d'une méthode d'extraction de la matière humique du sol. Science du Sol (in French), 2, 15-24.

D’Angelo, E.M., Kovzelove, C.A. \& Karathanasis, A.D. 2009. Carbon sequestration processes in temperate soils with different chemical properties and management histories. Soil Science, 174, $45-55$.

Desjardins, T., Andreux, F., Volkoff, B. \& Cerri, C.C. 1994. Organic carbon and ${ }^{13} \mathrm{C}$ contents in soils and soil size-fractions, and their changes due to deforestation and pasture installation in eastern Amazonia. Geoderma, 61, 103-118.

Duchaufour, P. \& Jacquin, F. 1975. Comparaison des processus d'humification dans les principaux types d'humus forestiers. Bulletin de l'Association Française pour l'Étude du Sol (in French), 1, 29-36.

Figueiredo, A., Jucksch, I., Schaefer, C.E.G.R. \& Wendling, B. 2008. Determination of total organic carbon and nitrogen stocks and their fractions in an Ultisol under different land uses. Revista Brasileira de Ciência do Solo (in Portuguese), 32, 2091-2100.

Fisher, R.A. 2006. Statistical methods for research workers. Cosmo Publications, Delhi, India.

García-Gómez, A., Bernal Calderón, M.P. \& Roig, A. 2005. Organic matter fractions involved in degradation and humification processes. Compost Science \& Utilization, 13, 127-135.

Gough, L.J. 1964. Conifer resin constituents. Chemistry \& Industry, 50, 2059-2060.

Grünzweig, J.M., Sparrow, S.D., Yakir, D. \& Chapin III, F.S. 2004. Impact of agricultural land-use change on carbon storage in boreal Alaska. Global Change Biology, 10, 452-472.

Guitián, F. \& Carballas, T. 1976. Técnicas de análisis de suelos (in Spanish). Pico Sacro, Santiago de Compostela.

Hachicha, R., Hachicha, S., Trabelsi, I., Woodward, S. \& Mechichi, T. 2009. Evolution of the fatty fraction during co-composting of olive oil industry wastes with animal manure: maturity assessment of the end product. Chemosphere, 75, 1382-1386.

Hamer, U., Potthast, K. \& Makeschin, F. 2009. Urea fertilisation affected soil organic matter dynamics and microbial community structure in pasture soils of Southern Ecuador. Applied Soil Ecology, 43, 226-233.

Hutchinson, J.J., Campbell, C.A. \& Desjardins, R.L. 2007. Some perspectives on carbon sequestration in agriculture. Agricultural and Forest Meteorology, 142, 288-302. 
INEA. 1973. Determinaciones analíticas en suelos; normalización de métodos. Anales de Edafología y Agrobiología (in Spanish), 32, 1153-1172.

Jandl, G., Leinweber, P. \& Schulten, H.R. 2007. Origin and fate of soil lipids in a Phaeozem under rye and maize monoculture in central Germany. Biology \& Fertility of Soils, 43, 321-332.

Juo, A.S.R., Ayanlaja, S.A. \& Ogunwale, J.A. 1976. An evaluation of cation exchange measurements for soils in the tropics. Communications in Soil Science and Plant Analysis, 7, 751-761.

Kawasaki, S., Maie, N., Kitamura, S. \& Watanabe, A. 2008. Effect of organic amendment on amount and chemical characteristics of humic acids in upland field soils. European Journal of Soil Science, 59, 1027-1037.

Kianirad, M., Muazardalan, M., Savaghebi, G., Farahbakhsh, M. \& Mirdamadi, S. 2009. Effects of temperature treatment on corn cob composting and reducing of composting time: a comparative study. Waste Management \& Research (Online First), DOI: $10.1177 / 0734242 X 09342359$.

Kilmer, V.J. \& Alexander, L.T. 1949. Methods of making mechanical analyses of soils. Soil Science, 68, 15-24.

Knights, B.A. 1967. Identification of plant sterols using combined GLC/Mass spectrometry. Journal of Gas Chromatography, 5, 273282.

Kögel-Knabner, I., Hatcher, P.G., Tegelaar, E.W. \& de Leeuw, J.W. 1992. Aliphatic components of forest soil organic matter as determined by solid-state ${ }^{13} \mathrm{C}$ NMR and analytical pyrolysis. Science of the Total Environment, 113, 89-106.

Kononova, M.M. 1962. Soil organic matter. Pergamon Press, New York.

Kononova, M.M. 1982. Materia orgánica del suelo. su naturaleza, propiedades y métodos de investigación (in Spanish). Oikos-Tau Ediciones, Barcelona.

Kumada, K. \& Hurst, H.M. 1967. Green humic acid and its possible origin as a fungal metabolite. Nature, 214, 631-633.

de Leeuw, J.W. \& Largeau, C. 1993. A review of macromolecular organic compounds that comprise living organism and their role in kerogen, coal, and petroleum formation. In: Organic Geochemistry. Principles and Applications, Vol. 2 (eds M.H. Engel \& S.A. Macko), pp. 23-72. Plenum Press, New York.

Martin, F. 1975. Pyrolysis gas chromatography of humic substances from different origin. Zeitschrift fur Pflanzenernahrung und Bodenkunde, 4/5, 407-416.

Martin, F., Saíz-Jiménez, C. \& González-Vila, F.J. 1979. Pyrolysisgas-chromatography - mass-spectrometry of lignins. Holzforschung, 33, 210-212.

Melo, L.C.A., Faquin, V., Carvalho, R. \& Silva, C.A. 2007. Physical-chemical characterization and comparison of digestion methods of organic residues. Electronic dissertation, Universidade Federal de Lavras, Brazil.

Moucawi, J., Fustec, E., Jambu, P., Amblès, A. \& Jacquesy, R. 1981. Biooxidation of added and natural hydrocarbons in soils. Effect of iron. Soil Biology \& Biochemistry, 13, 335-342.

Naafs, D.F.W. 2004. What are humic substances?: a molecular approach to the study of organic matter in acid soils. Ph.D. Thesis, University of Utrecht, Netherlands.

Nascimento, V.M., Almendros, G. \& Fernandes, F.M. 1992. Soil humus characteristics in virgin and cleared areas of the Panamá river basin in Brazil. Geoderma, 54, 137-150.
National Institute of Standards and Technology (NIST). 1995. NIST/EPA/NIH Mass Spectral Database, Standard Reference Database 1a and the Nist Mass Spectral Search Program, Version 1a. NIST, Gaithersburg, MD.

Nelson, D.W. \& Sommers, L.E. 1982. Total carbon, organic carbon, and organic matter. In: Methods of soil analysis. Part 2. 2nd Ed. (eds. A.L. Page, D.H. Miller \& D.R. Keeney), pp. 539-579. Agronomy Monographs 9. ASA and SSSA, Madison, WI.

Nierop, K.G.J., Pulleman, M.M. \& Marinissen, J.C.Y. 2001. Management induced organic matter differentiation in grassland and arable soil: a study using pyrolysis techniques. Soil Biology \& Biochemistry, 33, 755-764.

Nip, M., Tegelaar, E.W., de Leeuw, J.W. \& Schenck, P.A. 1986. A new non-saponifiable highly aliphatic and resistant biopolymer in plant cuticles. Naturwissenschaften, 73, 579-585.

Page, A.L., Miller, R.H. \& Keeney, D.R. 1982. Replacement of exchangeable cations. Ammonium acetate method. In: Methods of Soil Analysis. Part 2. 2nd Ed. (eds. A.L. Page, D.H. Miller \& D.R. Keeney), pp. 160-165. Agronomy Monographs 9. ASA and SSSA, Madison, WI.

Pajares, S., Gallardo, J.F., Masciandaro, G., Ceccanti, B., Marinari, S. \& Etchevers, J.D. 2009. Biochemical indicators of carbon dynamic in an Acrisol cultivated under different management practices in the central Mexican highlands. Soil \& Tillage Research, 105, 156-163.

Pardo, M.T., Almendros, G., Kileo, E., Maliondo, S. \& Msanya, B. 2008. Cultivation-induced effects on the soil organomineral matrix and their bearing on crust development on two soil formations from Tanzania. Communications in Soil Science and Plant Analysis, 39, 65-81.

Puglisi, E., Nicelli, M., Capri, E., Trevisan, M. \& del Re, A.A.M. 2003. Cholesterol, $\beta$-sitosterol, ergosterol, and coprostanol in agricultural soils. Journal of Environmental Quality, 32, 466-471.

Quénéa, K., Derenne, S., Largeau, C., Rumpel, C. \& Mariotti, A. 2006. Influence of change in land use on the refractory organic macromolecular fraction of a sandy spodosol (Landes de Gascogne, France). Geoderma, 136, 136-151.

Rashidi, M. \& Seilsepour, M. 2008. Modeling of soil cation exchange capacity based on soil organic carbon. ARPN Journal of Agricultural and Biological Science, 3, 41-45.

Saíz-Jiménez, C. \& de Leeuw, J.W. 1986. Chemical characterization of soil organic matter fractions by analytical pyrolysis-gas chromatography-mass spectrometry. Journal of Analytical and Applied Pyrolysis, 9, 99-119.

Saíz-Jiménez, C. \& de Leeuw, J.W. 1987. Nature of plant components identified in soil humic acids. Science of the Total Environment, 62, 115-119.

Savage, S.M., Osborn, J., Letey, J. \& Heaton, C. 1972. Substances contributing to fire-induced water repellency in soils. Soil Science Society of America Proceedings, 36, 674-678.

Schnitzer, M. 1974. The methylation of humic substances. Soil Science, 117, 94-102.

Schnitzer, M. \& Schulten, H.R. 1995. Analysis of organic matter in soil extracts pyrolysis-mass spectrometry. Advances in Agronomy, 55, 167-217.

Schnitzer, M., McArthur, D.F.E., Schulten, H.-R., Kozak, L.M. \& Huang, P.M. 2006. Long-term cultivation effects on the quantity 
and quality of organic matter in selected Canadian prairie soils. Geoderma, 130, 141-156.

Skjemstad, J.O., Krull, E.S., Swift, R.S. \& Szarvas, S. 2008. Mechanisms of protection of soil organic matter under pasture following clearing of rainforest on an Oxisol. Geoderma, 143, 231242.

Skyers, J.K., Campbell, A.S. \& Walker, T.W. 1970. Contribution of organic carbon and clay to cation exchange capacity in a chronosequence of sandy soils. Plant and Soil, 33, 104-112.

Stevenson, F.J. 1982. Humus chemistry: genesis, composition, reactions. Wiley, New York.

Tegelaar, E.W., de Leeuw, J.W. \& Saiz-Jiménez, C. 1989. Possible origin humic substances. Science of the Total Environment, 81/82, $1-17$.

Traina, S.J., Novak, J. \& Smeck, N.E. 1990. An ultraviolet absorbance method of estimating the percent aromatic carbon content of humic acids. Journal of Environmental Quality, 19, 151153.
Valtinat, K., Bruun, H.H. \& Brunet, J. 2008. Restoration of oak forest: effects of former arable land use on soil chemistry and herb layer vegetation. Scandinavian Journal of Forest Research, 23, 513521.

Veldkamp, E. 1994. Organic carbon turnover in three tropical soils under pasture after deforestation. Soil Science Society of American Journal, 58, 175-180.

Wallis, M.G. \& Horne, D.J. 1992. Soil water repellency. Advances in Soil Science, 20, 91-146.

Walton, T.J. 1990. Waxes, cutin and suberin. Methods of Plant Biochemistry, 4, 105-158.

Wiley, J. 2005. Wiley registry of mass spectral data, 8th edn. Wiley, Chichester.

Wilson, M.A. 1987. NMR techniques and applications in geochemistry and soil chemistry. Pergamon, Oxford.

Zukowska, G. \& Flis-Bujak, M. 2002. Properties of humic acids of light soil fertilized with sewage sludge. Polish Journal of Soil Science, 35, 37-43. 